\section{Technology, production, and distribution of terminal classic molded-carved vases in the Central Maya Lowlands}

\author{
Carmen Ting, ${ }^{1}$ Christophe Helmke ${ }^{2}$ \\ 'Institute of Archaeology, University \\ College London, UK; ' ${ }^{2}$ Department of \\ American Indian Languages and Cultures, \\ Institute of Cross-cultural and Regional \\ Studies, University of Copenhagen, \\ Denmark
}

\section{Abstract}

The paper summarises the results of the technological and stylistic analyses of the moldedcarved ceramic vases from Altun Ha, and Pook's Hill, two archaeological sites located in Belize. The stylistic analysis of these vases indicates that the decorative modes and the tradition of manufacturing vases by molds date squarely to the Terminal Classic period (ca. AD 800-1000). The Terminal Classic period is one of transition, exhibiting dramatic socio-political changes in the Maya Lowlands. The technological analyses employ energy dispersive X-ray fluorescence (ED-XRF), thin-section petrography, scanning electron microscopy-energy dispersive spectrometer (SEM-EDS), to characterise the physical, mineralogical, and chemical properties of the molded-carved vases. Combining the results of the technological and stylistic analyses help to discriminate the production groups, reconstruct the manufacturing technology, characterise the organisation of production, and delineate distribution patterns. Our present findings reveal that the changes in the socio-political order during the Terminal Classic in the Maya Lowlands likely stimulated changes in the types and manner in which elite pottery was produced, as well as the mechanisms responsible for the distribution of such ceramics.

\section{Introduction}

What Mayanists call the Terminal Classic period (ca. $\mathrm{AD} 800-1000$ ) refers to the centuries following the florescence of Classic civilisation. Although the nature, events, and processes leading to the Terminal Classic period are still the subject of much heated debates, archaeologists generally tend to agree that it was a transitional period that witnessed changes, transitions, and transformations in all aspects of Maya society, especially as regards political organisation and ideologies (Aimers, 2007; Demarest et al., 2004). Alongside the disinte- gration of the institution of divine kingship, one of the most noticeable changes, in terms of material culture, is an accelerated decline in the quality and quantity of elaborately painted polychrome vases, one of the hallmarks of the Classic period. By the Terminal Classic, this Classic polychrome tradition had virtually disappeared and was eventually replaced by the molded-carved tradition (Aimers, 2004; Forsyth, 2005; Lopez Varela and Foias, 2005; Rands, 1973; Rice and Forsyth, 2004; Willey et al., 1967; Helmke and Reents-Budet, 2008). At present, three traditions or types of molded-carved vases have been identified and established in the literature, designated Pabellon, Sahcaba, and Ahk'utu', respectively (Smith, 1955, 1958; Smith and Gifford, 1966; Chase, 1994; Gifford and Kirkpatrick, 1996; Helmke et al., 1998; Helmke and Reents-Budet, 2008). Based on our analyses, we have found that the overwhelming majority of molded-carved ceramics found at both Altun Ha and Pook's Hill can be assigned to the Ahk'utu' Molded-carved type (Figure 1), based on the shape of the vessels and their diagnostic ceramic modes, as well as on the basis of the dedicatory glyphic phrases and distinctive iconographic programs (Graham et al., 1980; Helmke et al., 1998; Helmke, 2000a, 2000b; Helmke and Reents-Budet, 2008). These Ahk'utu' vases, being apt temporal markers of the Terminal Classic period, are useful in assessing the extent to which the changes that transpired in the Terminal Classic period impacted the technology, production, and distribution of the elite serving wares in the Maya Lowlands. Here we focus on the Ahk'utu' sherd assemblages from Altun Ha and Pook's Hill in order to discriminate between potential production groups; reconstruct the manufacturing technology; characterise the organisation of production; establish the distribution patterns; and delineate the mechanism(s) responsible for the intra- and intersite distributions of the Ahk'utu' vases.

\section{Archaeological context}

Our research focuses on the two largest assemblages of Ahk'utu' vases recovered in Belize, which were recovered by means of controlled excavations from the sites of Altun $\mathrm{Ha}$ and Pook's Hill (Figure 2). Altun Ha was a small but important and wealthy urban centre, which is located in the north-central coastal plain of Belize and is underlain by Eocene and Miocene limestone (Pendergast 1979, 1982, 1990). Pook's Hill is a plazuela group situated in the Roaring Creek Valley of western Belize, amidst the karstic foothills (mainly Cretaceous-Paleocene carbonate limestones) to the granitic Maya Mountains (Helmke, 2001, 2006a, 2006b). Like many sites in the Southern Lowlands, both Altun Ha and Pook's Hill exhibited signs of decline toward the end of the Classic period. For Altun Ha, the majori-
Correspondence: Carmen Ting, Institute of Archaeology, University College London, 31-34 Gordon Square, London WC1H 0PY, UK.

Tel./Fax: +44.79009.17186.

E-mail: k.ting@ucl.ac.uk

Keywords: pottery, Maya, technology, production, distribution.

Citation: Ting C, Helmke C, 2013. Technology, production, and distribution of terminal classic molded-carved vases in the Central Maya Lowlands. In: RH Tykot (ed.), Proceedings of the 38th International Symposium on Archaeometry - May $10^{\text {th }}-14^{\text {th }} 2010$, Tampa, Florida. Open Journal of Archaeometry 1:e9.

Acknowledgements: we would like to thank the UCL Overseas Research Scholarship and the UCL Graduate Research Scholarship for funding the research. The Pook's Hill Lodge and the Belize Valley Archaeological Reconnaissance Project are thanked for indispensable financial and logistical support during the course of the archaeological investigations at Pook's Hill (1999-2005). Warm thanks to Jaime Awe for the opportunity to export and study the molded-carved sherds that are the subject of this paper. We extend a special thanks to Elizabeth Graham, David Pendergast, and Mima Kapches for access to the Altun Ha collections at the Royal Ontario Museum. Our gratitude goes to Elizabeth Graham and Marcos MartinónTorres for their constructive comments on the manuscript.

Presented at the $38^{\text {th }}$ International Symposium on Archaeometry - May $10^{\text {th }}-14^{\text {th }} 2010$, Tampa, Florida.

This work is licensed under a Creative Commons Attribution 3.0 License (by-nc 3.0).

(c) Copyright C. Ting and C. Helmke, 2013

Licensee PAGEPress, Italy

Open Journal of Archaeometry 2013; 1:e9

doi:10.4081/arc.2013.e9

ty of the Ahk'utu' sherds were found in the terminal occupational debris of vaulted elite residential structures (Groups $\mathrm{C}$ and $\mathrm{E}$ ) or within plazuela groups (Groups J and K). Much like Altun Ha, the majority of the Ahk'utu' sherds at Pook's Hill were recovered from the debris and midden deposits associated with residential structures (Structures 1A, 1B, 2A and 2B), some of which were vaulted, whereas the remainder of the molded-carved sherds were recovered from the terminal ritual debris related to the use of the eastern shrine (Structure $4 \mathrm{~A})$ of the plazuela.

\section{Materials and Methods}

An integrated approach - which includes the application of various archaeometric tech- 
niques, namely ED-XRF, thin-section petrography, and SEM-EDS, coupled with the appropriate sampling, and statistical methods - has been devised for this research. Stratified sampling was used for sample selection, in which 21 Ahk'utu sherds were chosen from Altun Ha, and 16 from Pook's Hill. The application of stratified sampling involved the division of the whole assemblage into sampling fractions, on the basis of any variations in macroscopic examination of the color of the paste, the distribution of inclusions, the presence/absence of slip. Such sampling procedure ensured a more balanced representation of the paste variability within the assemblage (Drennan, 1996; Orton, 2000).

Energy dispersive X-Ray fluorescence (ED$\mathrm{XRF}$ ) was used to characterise the bulk chemical composition of the samples, which constitutes the basis for the demarcation of the production-related compositional groups. All samples were analysed by the ED-XRF housed at the UCL Wolfson Laboratories at the Institute of Archaeology. Twenty-eight elements were detected: $\mathrm{Na}, \mathrm{Mg}, \mathrm{Al}, \mathrm{Si}, \mathrm{P}, \mathrm{K}, \mathrm{Ca}, \mathrm{V}, \mathrm{Mn}, \mathrm{Cr}, \mathrm{Mn}$, $\mathrm{Fe}, \mathrm{Co}, \mathrm{Ni}, \mathrm{Cu}, \mathrm{Zn}, \mathrm{Ga}, \mathrm{As}, \mathrm{Br}, \mathrm{Rb}, \mathrm{Sr}, \mathrm{Y}, \mathrm{Zr}, \mathrm{Nb}$, $\mathrm{Ba}, \mathrm{Ce}, \mathrm{Pb}$, and $\mathrm{Th}$. After experimentation with various bivariate plots to identify the clearest grouping tendencies, 21 elements were selected and processed statistically using principal component analysis (PCA). The elements included for the statistical analysis were those named above excluding $\mathrm{Mg}, \mathrm{P}, \mathrm{Br}, \mathrm{Sr}, \mathrm{Y}, \mathrm{Nb}$, and Th.

Thin-section petrography was used to identify the mineralogical constituents of the samples (Freestone, 1995; Griffiths, 1999; Kilikoglou et al., 2002; Peacock, 1970). The identification of minerals by thin-section petrography is particularly important in this research because the underlying bedrock of Belize is predominately limestone, which has the potential effect of homogenising the chemical composition of the samples. The application of thin-section petrography, therefore, served to confirm and even refine the compositional groupings characterised by ED-XRF. Thin-section petrography was also used for recognizing some of the technical choices that were involved in the production of the pottery. For instance, the orientation of the voids and the inclusions is indicative of the forming technique; the color and the optical state of the clay matrix reflects the firing temperature and atmosphere. A modified version of Whitbread's ceramic thin-section petrography descriptive system (1995) was adopted here to document the petrographic data.

Scanning electron microscopy energy dispersive spectrometry (SEM-EDS) was employed to record the micromorphology, and to identify the composition of the slip layer of the samples. Images of surface texture and internal morphology produced by the second- ary electron detector (SE) served to determine the extent of vitrification, reflecting the temperature at which the pottery was fired (Maniatis and Tite, 1981; Tite and Maniatis, 1975; Tite et al., 1982; Wolf, 2002). Images of compositional variability produced by the backscattered electron detector (BSE), coupled with the analysis by the EDS, allowed us to identify the presence and the composition of the slip of the samples. Analyses were conducted on polished cross sections using a Hitachi S-3400N SEM (Hitachi, Tokyo, Japan) with an Oxford Instruments EDS, housed at the Wolfson Laboratories at the UCL Institute of Archaeology. The results reported here are presented as stoichiometric oxides and have been normalised to $100 \%$ to account for sample porosity and small drifts in beam intensity.

\section{Results}

\section{Compositional variability}

Four chemically distinct groups are recognised and are shown in the bivariate plot of the first and second principal components of the compositional data of all samples from Altun Ha and Pook's Hill by ED-XRF (Figure 3). The samples from Altun Ha display clearer grouping tendencies, which are divided into 3 separate groups; whereas those from Pook's Hill lack significant grouping tendencies and cluster into one group. Such patterning is reaffirmed by the results of the petrographic analysis.

For Altun Ha, Group 1 is the core group, which comprises the majority of the samples. These samples are characterised by significantly high bulk $\mathrm{Ca}$ concentration that ranges from 14 to $27 \%$. This group is characterised by the presence of medium- to fine-grained polycrystalline calcites, and quartz inclusions, and dark clay pellets, in a non-calcareous brown clay with low abundance of voids (Figure 4a). The orientations of the inclusions and voids are crudely aligned to the margin of the samples. The matrices of the samples are moderately optically active. Group 2 comprises only 4 samples, which also contain high bulk $\mathrm{Ca}$ concentration, varying from 16 to $27 \%$. Group 2 is distinguished from Group 1 by its relatively higher Fe concentration, as reflected in the color of the ceramic matrices, which appear to be reddish brown. Although Group 1 and Group 2 display similarities in terms of the alignment of inclusions and voids, and the optical state of the matrices, Group 2 is characterised by the presence of coarse-grained polycrystalline calcites, and quartz inclusions, and dark clay pellets, in a non-calcareous red-brown clay with low abundance of voids (Figure 4b). Group 3 comprises only 2 samples. Bulk Ca concentration is low which ranges from only 2 to $7 \%$, but the samples have relatively higher $\mathrm{Na}$ and $\mathrm{K}$ concentrations. This group is characterised by the presence of volcanic ash, quartz, biotite, and muscovite inclusions in a non-calcareous light brown clay with very low abundance of voids (Figure 4c). The orientations of inclusions and voids are crudely aligned to the margin of the samples. The matrices are optically inactive. For Pook's Hill, all samples have high bulk Ca concentration, ranging from $20 \%$ to $36 \%$, thereby exceeding the samples of Groups 1 and 2 from Altun Ha. This group is characterised by the presence of polycrystalline calcites, and quartz inclusions, and dark clay pellets in a non-calcareous brown clay with low abundance of voids (Figure 4d). Although clear grouping tendencies of the samples are lacking, the abundance and proportion of the inclusions in the coarse fraction $(>0.2 \mathrm{~mm}$ long diameter) and the fine fraction $(<0.2 \mathrm{~mm}$ long diameter) vary among samples. Such variations are likely caused by the inherent variations of natural clay source (Bishop et al., 1982; Rice, 1987). The orientations of the inclusions and the voids are crudely aligned to the margin of the samples. The matrices are moderately optically active to inactive.

\section{Technological variability}

Macroscopically, the samples of the calcitetempered groups, namely Group 1 and Group 2 from Altun Ha, and all samples from Pook's Hill, share similar physical attributes. The reddish yellow (5YR 6/6) color of their pastes suggests that they were fired in an oxidising atmosphere, but with varying degrees of oxidation, as shown in the presence of dark firing cores in some samples. These calcite-tempered groups were fired at relatively low temperatures, which are estimated to have been below $800^{\circ} \mathrm{C}$, as illustrated in the absence of vitrification of the calcite grains in the $\mathrm{SE}$ images on SEM (Figure 5a) (Maniatis and Tite, 1981). In contrast, signs of incomplete oxidation are lacking in the samples of Group 3 from Altun $\mathrm{Ha}$, which exhibit homogeneous pink (7.5YR 7/4) color through the cross section and an absence of dark cores. The absence of crystalline calcite in these samples makes the assessment of firing temperature difficult, but the temperature cannot have been too high judging from the flaky structure of clay minerals visible in SE images (Figure 5b).

Although the exterior surfaces of all moldedcarved vases were once slipped, slip layer is preserved on only 3 samples from Group 1 and 1 from Group 3 of Altun $\mathrm{Ha}$, as well as 4 samples from the Pook's Hill. The slips on the samples from Altun Ha's Group 1 and Pook's Hill were applied after molding, but before carving, as evident in the absence of slip in the troughs; whereas the slip on the sample from Altun Ha's Group 3 was applied to the surface after molding and carving, as shown in the presence of 
slip in both the ridges and troughs of the carving lines. In all cases, slip could be easily detected as a homogeneous layer, with partially vitrified microstructure, adhering to the surface of the sherd in the BSE images on the SEM (Figure 6). SEM-EDS analyses of the slips and their associated matrices reveal that only slight variation in composition exists between the two, which is probably caused by the removal of impurities from the clay during preparation of the slip. The slip layers generally have relatively higher $\mathrm{FeO}$, which may be essential to obtaining the preferred red-toorange colour of the slip on the exterior surfaces of the molded-carved vases.

\section{Discussion}

\section{Discrimination of potential produc- tion groups}

The rationale behind the physiochemical analyses of ceramic materials is that potters' recipes of clay and tempers are unique to individual workshops and potters, thus their products are chemically and mineralogically distinguishable from those of other pottery producers within the region and even among different potters in the same community (Ball, 1993; Rice, 2009). We, therefore, propose that the four distinct compositional groups represent the products of four potential production groups, each of which produced molded-carved vases according to its own ceramic recipe. With reference to the local geology, as well as working under the assumption that the materials which occur in highest frequencies tend to be local (Reents-Budet et al., 1994; ReentsBudet, 2000), we suggest that the vases of Group 1 and Group 2 from Altun Ha, and those from Pook's Hill were produced locally.

\section{Reconstruction of manufacturing technology}

The manufacturing technology exhibited by the Ahk'utu' vases is largely the same across the four production groups. Molding was the primary forming techniques in which the clay was pressed against paired concave molds. This hypothesis is supported by the identification of voids aligning with the margins of the thin sections, as well as the recovery of two ceramic mold fragments depicting the standard iconography of Pabellon vases at Altar de Sacrificios (Adams, 1971) and an additional one at Seibal (Willey et al., 1978).

With the exception of Group 3 from Altun $\mathrm{Ha}$, all other samples from Altun Ha and Pook's Hill were covered with thin layers of slips, which were carved during the leather-hard stage as is shown by the presence of smooth beds and sharp margins along the carving lines

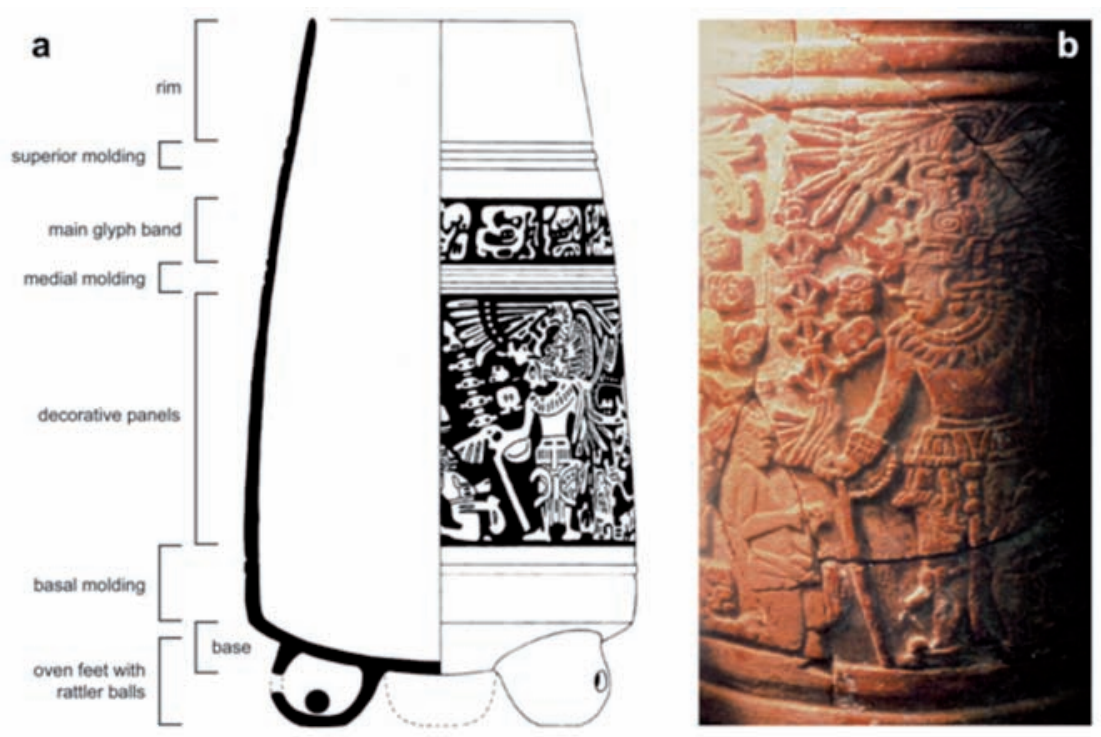

Figure 1. The Ahk'utu' vases; a) the profile of the vase, b) a panel showing the decoration on the vase. Photograph by courtesy of Dorie Reents-Budet.

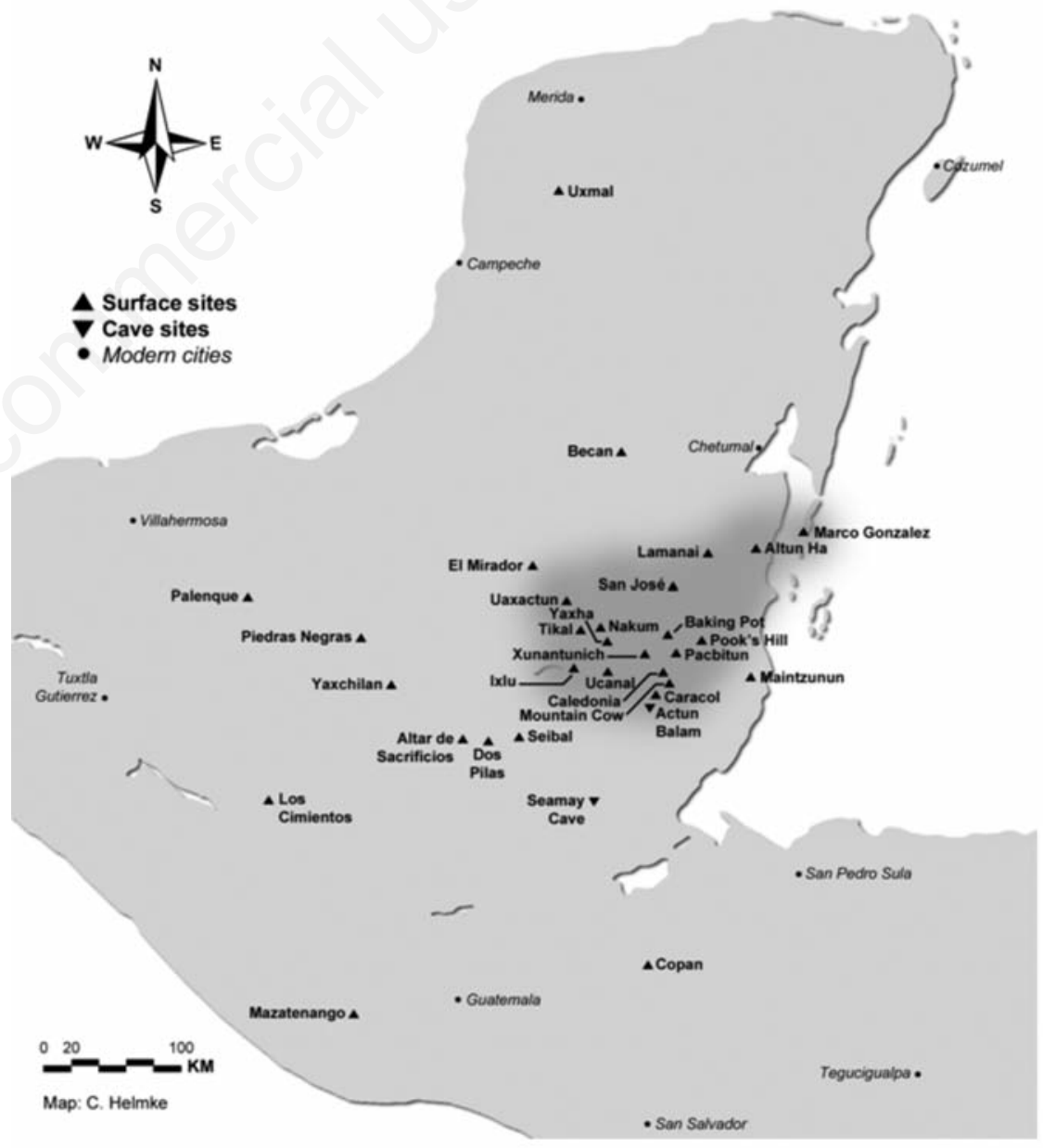

Figure 2. Map of the Maya area showing the location of the archaeological sites where molded-carved ceramics have been found, including Altun Ha and Pook's Hill. The shaded area marks the zone wherein Ahk'utu' Molded-carved ceramics predominate. 
under the stereomicroscope in most samples. Once the clay and the slip had dried, a planorelief carving method was used to accentuate and refine the molded design. This order of slip application and carving was reversed in the case of Altun Ha's Group 3, with slip after carving. The Group 1 and Group 2 vases from Altun $\mathrm{Ha}$ and the vases from Pook's Hill were fired at temperatures below $800^{\circ} \mathrm{C}$ in an incomplete oxidizing atmosphere as indicated by the presence of dark firing cores and the moderately gleaming effect upon rotation in nearly all thin sections. The firing temperature of Group 3 vases from Altun $\mathrm{Ha}$ is yet to be determined, but these vases appear to have been fired in an atmosphere that resulted in complete oxidation. Low firing temperatures, varying degrees of oxidation and uneven access to air suggest that the Ahk'utu' vases were fired in a non-kiln, open firing structure (Rye, 1981).

\section{Characterisation of the organisa- tion of production}

In the absence of archaeological evidence of production and firing locales, the organisation of production of the molded-carved vases from Altun Ha can be assessed on the basis of indirect evidence, namely standardisation, skill, and efficiency, as proposed by Costin (1991). Standardisation is measured on the basis of the compositional and technological variability in this research. In spite of the technical differences noted between the four groups (in temper, order of carving/slipping, and firing), they all broadly conform to the same manufacturing technology. These similarities indicate that some technological information may have been shared by all producers, but more importantly, they also suggest that all potting groups aimed to manufacture pottery that would be recognised by consumers over a broad area on the basis of color, shape, and pictorial representation. Consumer demands can therefore be seen to have influenced what could be said to be the type of the vessel, as is independently supported by the emic designations of the vases recorded in the glyphic texts that adorn each vase (Helmke and Reents-Budet, 2008). The co-existence of four production groups reflects, however, distinct localised community traditions of resource use and manufacture.

The other two parameters - skill and efficiency - are influenced by the political, economic and social conditions under which production is organised, and are even harder to address archaeologically (Costin, 1991; Costin and Hagstrum, 1995). It is generally assumed the production of objects that have significant social and political value required more sophisticated skill and thus lower efficiency level. However, the Ahk'utu' vases were efficiently produced and in large numbers as is evidenced by the use of molds, which required relatively lower skill level and reduced the time, cost, and labor in producing these vases. We believe that competing elites required the production of Ahk'utu' vases as political and social currency in a more efficient manner to build alliances and legitimise their precarious positions during the political instability and

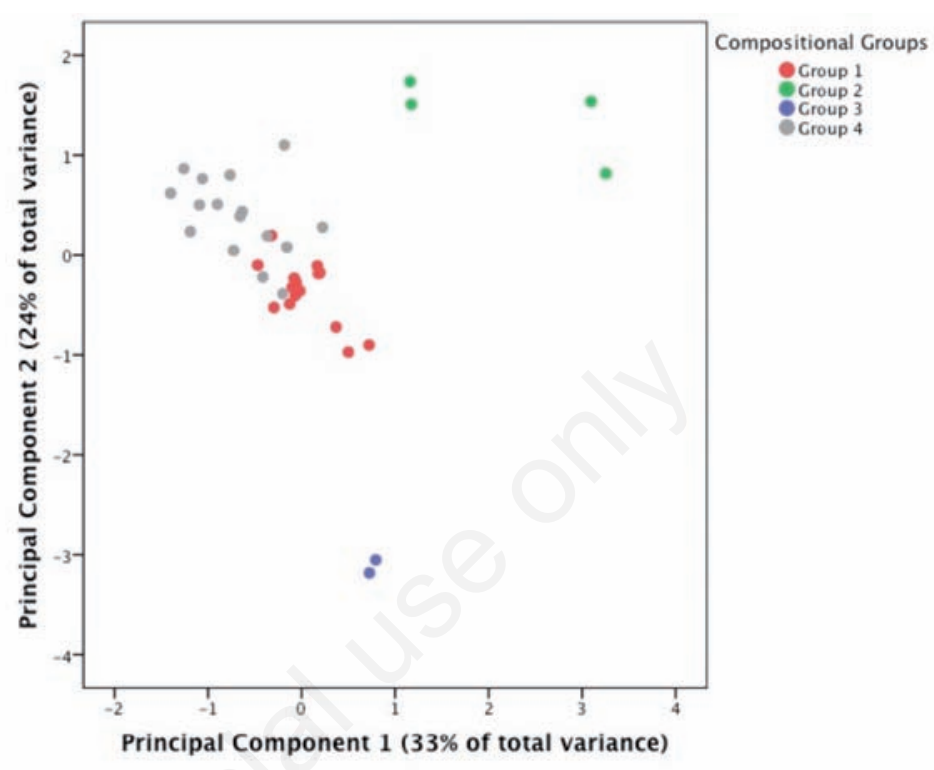

Figure 3. Bivariate plot based on the first two principal components of the normalised energy dispersive X-ray fluorescence data on the compositions of all samples from Altun $\mathrm{Ha}$ and Pook's Hill.
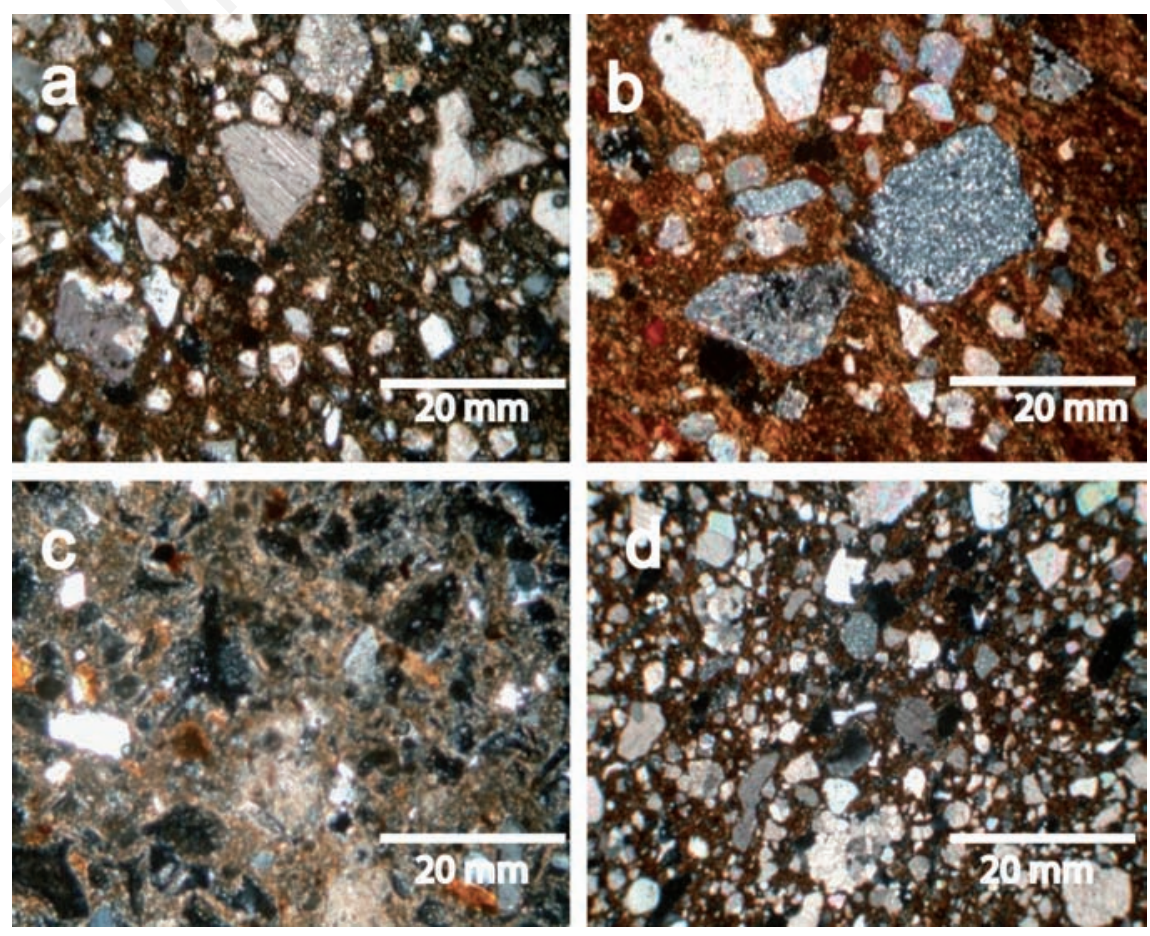

Figure 4. Photomicrographs showing the petrography of samples of a) Group 1; b) Group 2; c) Group 3 from Altun Ha; and d) Pook's Hill. 
consumption. Despite the general assumption that goods with special values can potentially travel greater distance (Fry, 1981; Arnold, 1981), the patterns of the Ahk'utu' vases in large measure suggest otherwise. With the exception of Group 3 vases from Altun Ha, all other groups from both Altun Ha and Pook's Hill, were manufactured using local resources and were deposited in local contexts. On the one hand, the co-existence of Group 1 and Group 2 at Altun $\mathrm{Ha}$ indicates the presence of internal exchange of vases within the broader community. At present, little or no exchange of the Ahk'utu' vases between sites can be identified, but the presence of the non-local Group 3 at Altun $\mathrm{Ha}$ is suggestive of possible exchange between Altun Ha and other centers in the Maya Lowlands. This possibility is supported by the emic label attributed to these vases, since the glyphs decorating the vessels clearly designate these as ahk'utu', which can loosely be translated as gift-implements (Helmke, 2001; Helmke and Reents-Budet, 2008). The overall exchange pattern highlights that the Ahk'utu' vases were mostly engaged in localised distribution rather than long-distance exchange. We therefore interpret such patterning as the result of attempts by lesser elites to regulate the circulation of the Ahk'utu' vases by means of re-distribution and gift exchange via ritual practices, such as feasting, within their respective communities. The acts of redistribution and gift exchange of the Ahk'utu' vases involved not only the exchange of valued goods - both within and across different social strata - but also the circulation of the associated social values, ritual practices and ideologies embedded in these
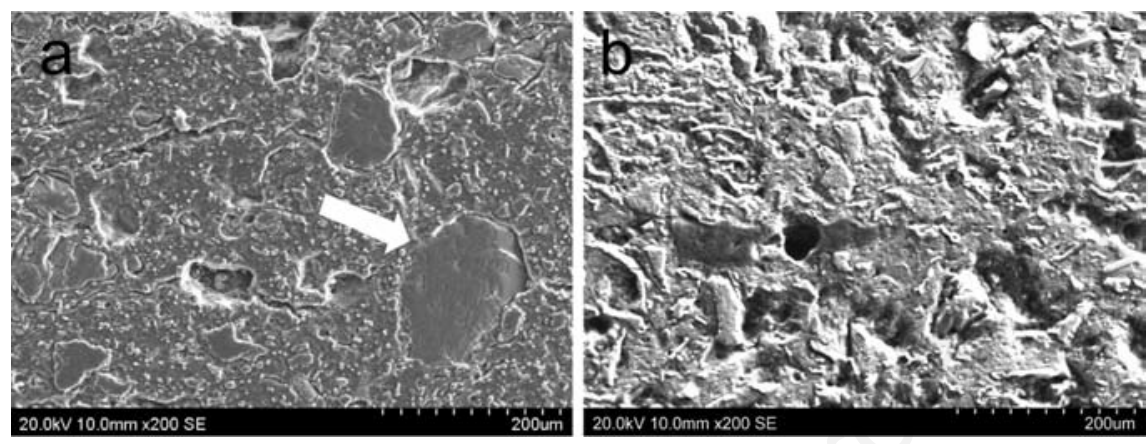

Figure 5. Secondary electron images by scanning electron microscopy showing a) the clear boundary of calcite grains as indicated by arrow, and b) flaky structure of clay minerals.
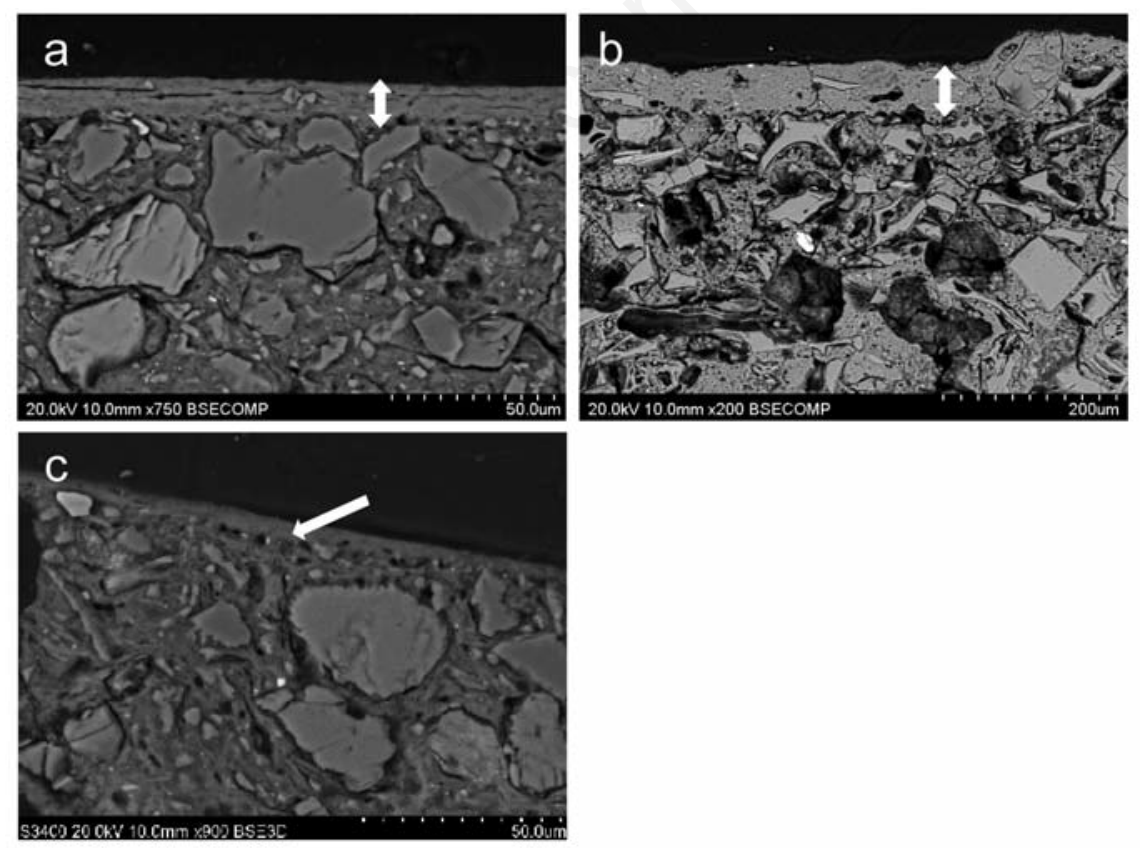

Figure 6. Backscattered electron images by scanning electron microscopy showing slip layers of samples (arrows) of Group 1 (a), Group 3 from Altun Ha (b), and Pook's Hill (c).

vases. In this way, the redistribution of the Ahk'utu' vases served as an integral part to the formulation of political strategies, the maintenance of economic exchange, and the materialisation of social values and relations at Altun Ha and Pook's Hill.

\section{Conclusions}

Based on the results of the technological and stylistic analyses, we propose that alterations in the socio-political order during the Terminal Classic period had profound impact on the technology, production and distribution of elite serving wares. In terms of technology, and production, the use of molds in the massproduction of Ahk'utu' vases is a drastic departure from the former polychromatic tradition, which was centralised and attached to royal courts and exhibits the highest degree of craft specialisation, in which each and every single vase was a unique masterpiece. It is far from coincidental that the appearance of moldedcarved ceramics in the Maya Lowlands matches the time when the authority of centralised governments began to wane. In terms of distribution, instead of establishing alliances with other centres as evident in the inter-site exchange of polychrome vases during the Late Classic period, the lesser elites focused on stabilizing internal relations of more localised networks during the Terminal Classic, as is reflected in the exchange patterns of the Ahk'utu' vases documented at Altun $\mathrm{Ha}$ and Pook's Hill. As such elites throughout the Southern Lowlands continued to foster shared value structures, but increasingly there was greater flexibility and fluidity in the production of the materials that reinforced this structure.

\section{References}

Adams REW, 1971. The ceramics of Altar de Sacrificios. Harvard University, Cambridge.

Aimers JJ, 2004. Cultural change on a temporal and spatial frontier: ceramics of the Terminal Classic to Postclassic transition in the upper Belize River Valley. Archaeopress, Oxford.

Aimers JJ, 2007. What collapse? Terminal Classic variation in the Maya Lowlands. $\mathrm{J}$ Archaeol Res 15:329-77.

Arnold DE, 1981. Localized exchange: an ethnoarchaeological perspective. In: Fry RE, editor. Models and methods in regional exchange. Society for American Archaeology, Washington D.C., pp 147-50.

Ball JW, 1993. Pottery, potters, palaces, and polities: some socioeconomic and political implications of Late Classic Maya ceramic 
industries. In: J.A. Sabloff, J.S. Henderson (eds.) New perspectives on Classic Maya civilization: lowland societies in the eighth century A.D. Dumbarton Oaks Research Library and Collection, Washington D.C., pp 243-72.

Bishop RL, Rands RL, Holley GR, 1982. Ceramic compositional analysis in archaeological perspective. Advances in archaeological method and theory 5:275-330.

Chase AF, 1994. A contextual approach to the ceramics of Caracol, Belize. In: D.Z. Chase, A.F. Chase (eds.) Studies in the archaeology of Caracol, Belize. Pre-Columbian Art Research Institute, San Francisco, pp 15782.

Costin CL, 1991. Craft specialization: issues in defining, documenting, and explaining the organization of production. Archaeological Method and Theory 3:1-56.

Costin CL, Hagstrum MB, 1995. Standardization, labour investment, skill, and the organization of ceramic production in Late Prehispanic Highland Peru. Am Antiquity 60:619-39.

Demarest AA, Rice PM, Rice DS, 2004. The terminal classic in the Maya Lowlands: collapse, transition, and transformation. University Press of Colorado, Boulder.

Drennan RD, 1996. Statistics for archaeologists: a common sense approach. Plenum Press, New York.

Forsyth D, 2005. A survey of terminal classic ceramic complexes and their socioeconomic implications. In: S.L. Lopez Varela, A.E. Foias (eds.) Geographies of power: understanding the nature of Terminal Classic pottery in the Maya Lowlands. Archaeopress, Oxford, pp 7 22.

Freestone I, 1995. Ceramic petrography. Am J Archaeol 99:111-5.

Fry RE, 1981. Models of exchange for major shape classes of Lowland Maya pottery. In: R.E. Fry (ed.) Models and methods in regional exchange. Society for American Archaeology, Washington D.C., pp 3-18.

Gifford C, Kirkpatrick M, 1996. [Ceramica de Cultura Maya]. [Book in Spanish]. Laboratory of Anthropology, Temple University, Philadelphia.

Graham E, McNatt L, Gutchen MA, 1980. Excavations in footprint cave, Caves Branch, Belize. J Field Archaeol 7:153-72.

Griffiths DR, 1999. The role of interdisciplinary science in the study of ancient pottery. Interdiscipl Sci Rev 24:289-300.

Helmke CGB, 2000a. Notes on Terminal Classic Molded-carved ceramics from Pacbitun, Cayo, Belize. Typescript. Copy on file at the Archaeology Laboratory, Trent University, Peterborough.

Helmke CGB, 2000b. Terminal Classic Moldedcarved vases from structures 193, 198 and 199, Baking Pot, Cayo District, Belize. In: C.S. Griffith, R. Ishihara, J.J. Awe (eds.) The
Western Belize Regional Cave Project: a report of the 1999 Field Season. Department of Anthropology, University of New Hampshire, Durham, pp 15-42.

Helmke CGB, 2001. The last supper: competitive feasting and the Terminal Classic Moldedcarved ceramic tradition in the Central Maya Lowlands. MA Thesis. Institute of Archaeology, University College London, London.

Helmke CGB, 2006a. A report of the 2005 season of archaeological investigations at Pook's Hill, Cayo District, Belize. In: C. Helmke, J.J. Awe (eds.) The Belize Valley Archaeological Reconnaissance Project. Institution of Archaeology, Belmopan, pp 39-92.

Helmke CGB, 2006b. A summary of the 19992002 seasons of archaeological investigations at Pook's Hill, Cayo District, Belize. Research Reports in Belizean Archaeology 3:173-91.

Helmke CGB, Colas PR, Awe JJ, 1998. Comments on the typology, epigraphy, and iconography of the Actun Tunichil Muknal vase and Belize Valley Modeled-carved vessels. In: J.J. Awe (ed.) The Western Belize Regional Cave Project: a report of the 1997 field season. Department of Anthropology, University of New Hampshire, Durham, pp 93-140.

Helmke CGB, Reents-Budet D, 2008. A Terminal Classic Moulded-carved ceramic type of the Eastern Maya Lowlands. Research Reports in Belizean Archaeology 5:37-49.

Kilikoglou V, Hein A, Mainatis Y, 2002. Modern trends in scientific studies on ancient ceramics. In: Papers presented at the 5th European Meeting on Ancient Ceramics, Athens 1999. Archaeopress, Oxford.

Lopez Varela SL, Foias AE, 2005. An introduction to geographies of power. In: S.L. Lopez Varela, A.E. Foias (eds.) Geographies of power: understanding the nature of Terminal Classic pottery in the Maya Lowlands. Archaeopress, Oxford, pp 1-6.

Maniatis Y, Tite MS, 1981. Technological examination of Neolithic-Bronze Age pottery from Central and Southeast Europe and from the Near East. J Archaeol Sci 8:59-76.

Orton C, 2000. Sampling in archaeology. Cambridge University Press, Cambridge.

Peacock DPS, 1970. The scientific analysis of ancient ceramics: a review. World Archaeol 1:375-89.

Pendergast DM, 1979. Excavations at Altun Ha, Belize, 1964-1970. Vol. 1. Toronto: Royal Ontario Museum.

Pendergast DM, 1982. Excavations at Altun Ha, Belize, 1964-1970. Vol. 2. Toronto: Royal Ontario Museum.

Pendergast DM, 1990. Excavations at Altun Ha, Belize, 1964-1970. Vol. 3. Toronto: Royal Ontario Museum.

Rands RL, 1973. The Classic collapse in the Southern Maya Lowlands: chronology. In: T.P. Culbert (ed.) The Classic Maya collapse. A school of American research book. University of New Mexico, Albuquerque, pp 43-62.

Reents-Budet D, 2000. Feasting among the Classic Maya: evidence from pictorial ceramics. In: J. Kerr (ed.) The Maya vase book. Kerr Associates, New York, pp 1022-38.

Reents-Budet D, Bishop RL, MacLeod B, 1994. Painting styles, workshop locations and pottery production. In: D. Reents-Budet (ed.) Painting the Maya universe: royal ceramics of the classic period. Duke University Press, Durham, pp 164-233.

Rice PM, 1987. Pottery analysis: a sourcebook. The University of Chicago Press, Chicago.

Rice PM, 2009. Late Classic Maya pottery production: review and synthesis. J. Archaeol Method Theory 16:117-56.

Rice PM, Forsyth D, 2004. Terminal ClassicPeriod Lowland ceramics. In: A.A. Demarest, P.M. Rice, D.S. Rice (eds.) The Terminal Classic in the Maya Lowlands: collapse, transition, and transformation. University Press of Colorado, Boulder, pp 28-59.

Rye OS, 1981. Pottery technology: principles and reconstruction. Taraxacum, Washington D.C.

Smith RE, 1955. Ceramic sequence at Uaxactun, Guatemala. Tulane University, New Orleans.

Smith RE, 1958. The place of fine orange pottery in Mesoamerican Archaeology. Am Antiquity 24:151-60.

Smith RE, Gifford JC, 1966. Maya ceramic varieties, types, and wares at Uaxactun: supplement to ceramic sequence at Uaxactun. Tulane University, New Orleans.

Tite MS, Freestone IC, Meeks ND, Bimson M, 1982. The use of scanning electron microscopy in the technological examination of ancient ceramics. In: J.S. Olin, A.D. Franklin (eds.) Archaeological ceramics. Smithsonian Institution Press, Washington D.C., pp 109-20.

Tite MS, Maniatis Y, 1975. Examination of ancient pottery using the scanning electron microscope. Nature 257:122-3.

Whitbread IK, 1995. The collection, processing and interpretation of petrographic data. In: I.K. Whitbread (ed.) Greek transport amphorae: a petrological and archaeological study. British School at Athens, London, pp 365-95.

Willey GR, Culbert TP, Adams REW, 1967. Maya Lowland ceramics: a report from the 1965 Guatemala City conference. Am Antiquity 32:289-315.

Willey GR, Wilk RR, Sidrys R, Nelson FW, Holmes RD, Feldman LH, Olsen SJ, 1978. Excavations at Seibal, Department of Peten, Guatemala: artifacts. Harvard University, Cambridge.

Wolf S, 2002. Estimation of the production parameters of very large medieval bricks from St. Urban, Switzerland. Archaeometry 44:37-65. 